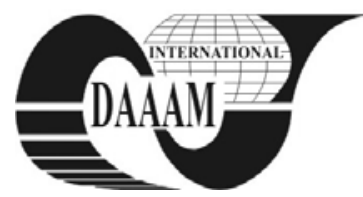

\title{
HYDROMECHANICAL CONSTANT SPEED DRIVE FORWIND-DRIVEN GENERATORS
}

\author{
MIKHAYLOV, M[axim]; LARCHIKOV, I[lya] A[lksandrovich]; YUROV, A[ndrej] V[asilevich]; CVETKOV, \\ V[ladimir] \& STAZHKOV, S[ergey]
}

\begin{abstract}
The main object of the project is development of a specialized constant speed drive on the voluminous hydromechanical transmission basis and research of its working modes as electricity generation system drive for wind electricity generator. This drive is designed for transformation of variable wind wheel speed into constant synchronous generator speed that makes it possible to exclude expensive and less effective unit of electric current converters from the generator composition
\end{abstract}

Key words: alternative energy, wind power, mechatronics, hydraulics, control systems

\section{INTRODUCTION}

Nowadays number of world's resources of traditional energy resources is severely limited. It (this) will lead to serious energy problems in the near future. Alternative energy sources such as wind power acquire a large role in the situation. The total capacity of all turbines in the world increased 6 times from 2000 to 2009 (http://www.gwec.net, 2009) and amounted to 157 GWt (Strube, 2010). Now leaders in recycling wind power are the U.S. (35 GWt), Germany (25.8 GWt) and China (25.1 GWt) (http://www.ewea.org, 2007).

Wind turbines are high-tech systems and the process of their creation is full of complex science and engineering problems. Creators of wind generators constantly struggle to improve energy efficiency and economic installations.

The system converting mechanical energy of wind turbines rotation in to electricity (generation system) is the main component turbine and determines its effectiveness. The system is designed to convert non-constant wind energy in conditionally constant electrical energy. The main problem and task of wind energy is the realization of this process with maximum efficiency.The alignment of electricity running through power electronics. But this electronics has some major drawbacks: high weight, size, cost and complexity.

\section{PROPOSED SOLUTION}

The disadvantages of generation system construction make engineers to find new and more effective solutions. The same time decrease of its component complexity, mass and dimensions is the main condition while keeping high level of generator's coefficient of efficiency. It is possible to get the required effect at the expense of using hydromechanical constant speed drive (HCSD). HCSDs are designed for stepless transformation of variable speed of the input shaft into constant speed of the output shaft and its maintenance. The HCSD can be directly connected with the generator output shaft that will ensure its constant speed and correspondingly constant value of produced voltage.

The HCSD power unit consists of input shaft, three-link compensation gear and output shaft, which are connected through power transmissions. The variable moment that is gathered by wind wheel is transformed during the operation into constant moment by the compensation gear. This moment in turn comes to the generator shaft. Due to its kinematic scheme the compensation gear has variable transmission ratio. Variable transmission ratio has to change depending on input moment value to maintain constant moment on output. The executable hydraulic circuit is designed for working off the necessary transmission ratio of compensation gear and for reinforcement of transitional moment. The hydraulic circuit includes unregulated hydraulic motor that is kinematically connected with one of the compensation gear links, and regulated hydraulic pump that is hydraulically connected with the first generator. The use of hydraulic drive significantly increases the drive specific output compared to other types of drives of similar dimensions while maintaining a high level of coefficient of efficiency (Babaev et al., 2000).

The drive is equipped with speed sensors of input and output shafts, turning angle of controlled pump cylinder unit and pressure sensors of hydraulic fluid in hydraulic circuit and hydraulic generators. The feedback signal of these sensors comes into the control system (Mikhaylov et al., 2009).

Primary analysis of main characteristics of the generation system based on HCSD with traditional system based on power electric transducers showed that the offered solution has a better characteristic of specific output while other basic parameters being equal. In fact it means that having similar outputs of the energy generation systems, the system based on HCSD will have significantly lower indicators of weight and dimensions, that will lead to the weight decrease of the wind generator body (and consequently to the lightening and reduction in cost of transportation and installation), to the decrease of its shielding and to the possibility of installation of a greater diameter screw. The main results of the analysis are presented in Tab. 1.

\begin{tabular}{|l|c|c|}
\hline \multicolumn{1}{|c|}{ Parametr } & HCSD & Power electric \\
\hline Efficiency & $92-95 \%$ & $95 \%$ \\
\hline Accuracy & $4 \%$ & $3-4 \%$ \\
\hline Specific power & $1,6-1,8 \mathrm{~kg} / \mathrm{kW}$ & $4 \mathrm{~kg} / \mathrm{kW}$ \\
\hline Relative volume & $0,0029 \mathrm{~m}^{3} / \mathrm{kW}$ & $0,0072 \mathrm{~m}^{3} / \mathrm{kW}$ \\
\hline
\end{tabular}

Tab. 1 . The main results of the characteristics analysis

\section{SCIENTIFIC PROBLEM}

Operation of volume hydromechanical transmission (VHT) in the HCSD mode has a series of important features. In particular, from a perspective of the volume hydromechanical drive it is the unusual operation of hydraulic generators within the drive: angular speed of the motor changes to zero and a hydraulic pump parameter takes zero values, i.e. in the process of changing the gear ratio the operation modes of hydraulic generators are changing while the operation modes of input and output links of transmission are constant. This process has a negative impact on the value of the HCSD output shaft 
positioning accuracy, which is one of the determinants of performance quality of the drive. The above aspects of the drive operation are nowadays the subject of scientific researches.

\section{HCSD RESEARCH}

The main objective of the presented HMCSD research is to identify the requirements for obtaining a given accuracy to maintain a stable rate, while ensuring the minimum weight and dimensions at maximum coefficient of efficiency of the drive and to work out the requirements for the control system on the basis of received data.

At the preliminary stage of research the design work on HCSD with specified parameters was carried out. The construction of mechanical compensation gear was designed and for this purpose the kinematic scheme was chosen and justified, layout of gears was worked out, necessary calculations and modelling of compensation gear with CAD were made. The hydraulic circuit of the drive was designed at the next stage.

An important stage of research was the development of both static and dynamic mathematical models of the drive. Models are based on the conformities for calculating the kinematic, stress and hydraulic characteristics of VHT in the HCSD mode, as well as the basic equations of its motion. As initial data the model obtained hydraulic characteristics of the hydraulic circuit and mechanical characteristics of the compensation gear of the designed drive, the law of velocity change on the drive input and the required velocity on the output and also the hydraulic fluid parameters.

It can be seen from the results of these calculations that during a regulation of the pump parameter propagation the unregulated motor passes through the area of zero turns, changing its direction of rotation. As noted above, this is a nonspecific mode of operation and it creates a main difficulty in designing drives of this type. It is explained by the fact that at the boundaries of the zone of zero velocity the hydraulic motor stops, as the whole volume of feeding is to compensate the leak of the fluid (the value of volume loss increases sharply). Within this zone the generator is not able to compensate for leakages. That's why along with the hydraulic motor speed the pressure in the hydraulic drive is gradually reducing to zero. The speed of drive output shaft decreases in the period when hydraulic generator passes through the zero zone. This leads to a failure of the drive output shaft rotation rate and consequently to the failure of generator rotation speed. It is important that the failure of the generator speed should not exceed $4 \%$, as this accuracy determines the quality of produced AC current, especially its frequency stability. Therefore, in future it is necessary, firstly, to determine the importance of emerging leaks in the drive, secondly, to determine how they affect the speed of the motor while determining the value of its area of zero velocities and, thirdly, how the size of this area affects the value of output speed.

This mathematical model allows calculating the basic characteristics of the drive including the border area of zero velocities. But despite this, it can not provide an idea of the processes occurring within the area of zero velocities that are necessary to understand how they affect the accuracy of positioning of the output link. This is due to the fact that much dependence within this area becomes strongly nonlinear and no longer reflects the real processes. In this regard the need for full-scale experiment appeared, so a research stand was developed and implemented for this purpose.

The stand consists of HCSD, an electric motor combined with a volume hydraulic drive (a simulation motor with variable speed rate), and an electrical generator. A series of preliminary experiments was carried out on the stand, which aimed to define an area of zero velocities of a motor at a constant motor speed and variable load on the output shaft. As a result of a series of preliminary experiments, the data confirming the results of calculations using the mathematical model was obtained. During the main stage of the experiments it is planned a number of tests of the drive operating in the HCSD mode to identify and qualitatively assess the impact of an area of zero velocities on the accuracy of positioning of the output link.

\section{EXPECTED RESULTS}

Information, obtained as a result of ongoing researches, will serve as a basis for designing of the control system for HCSD, which will take into account reversal of the motor and offset the impact area of zero velocities on the drive accuracy. Partial compensation of the area can meet the conditions of the drive operating if the velocity jump will be within the normal range.

In addition to researches, there is the task of creating of such a methodology of design and calculation of HCSD that would allow reliably predict the accuracy of maintaining rotation speed in transition and stationary modes, weight and dimension parameters and coefficient of efficiency of the drive without the design development transmission, i.e. at the stage of choosing the structural and kinematic drive schemes.

\section{PRACTICAL APPLICATION}

Developed HCSD has a high practical value as a drive for the system of wind energy generation. Comparative analysis of the solution with traditional systems has shown that the development has the best performance.

In general, application of this technology may have the following results, such as an increase of efficiency and reduce of production, installation and operation costs of wind turbines that will lead to cheaper power generation. At present the high cost of electricity generated by wind energy is a factor that hinders the widespread use of wind power generators. Prospectivity and usefulness of this technology also confirm the safety and ecological compatibility of wind energy, as well as problems associated with operation of nuclear power plants (for example, accident at "Fukushima-1") and power industry based on processing of natural resources.

\section{CONCLUSION}

The use of hydromechanical constant-speed drives is a promising line of development of wind energy. This will get rid of the massive and expensive elements in the system of energy generation (precision multistage multiplier, rectifier on the power electronics base), reducing its weight and dimension, in order to reduce of the producting and operating costs.

\section{REFERENCES}

Babaev, O.M.; Ignatov, L.N.; Kistochkin, E.S. \&Cvetkov, V.A. (2000).Hydromechanical power transmissions, Mechanical engineering, St.-Petersburg, Russia

Mikhaylov, M.; Kopaev, S. \&Stazhkov S. (2009). The automated neural-network control system of the hydraulic constant-speed drive, Proceedings of the 20th International DAAAM Symposium,Katalinic, B. (Ed.), pp. 1605-1606, ISBN 978-3-901509-70-4, Austria Center Vienna, Vienna, Austria, November 2009, DAAAM International Vienna, Vienna

Strube, O. (2010). Global Wind Installations Boom, Available from: http://www.renewableenergyworld.com Accessed: 2010-03-10

*** (2009) http://www.gwec.net - The Global Wind Energy Council, Accessed on: 2010-06-05

*** (2007) http://www.ewea.org - The European Wind Energy Association, EWEA Annual Report 2007, Accessed on: 2010-06-17 